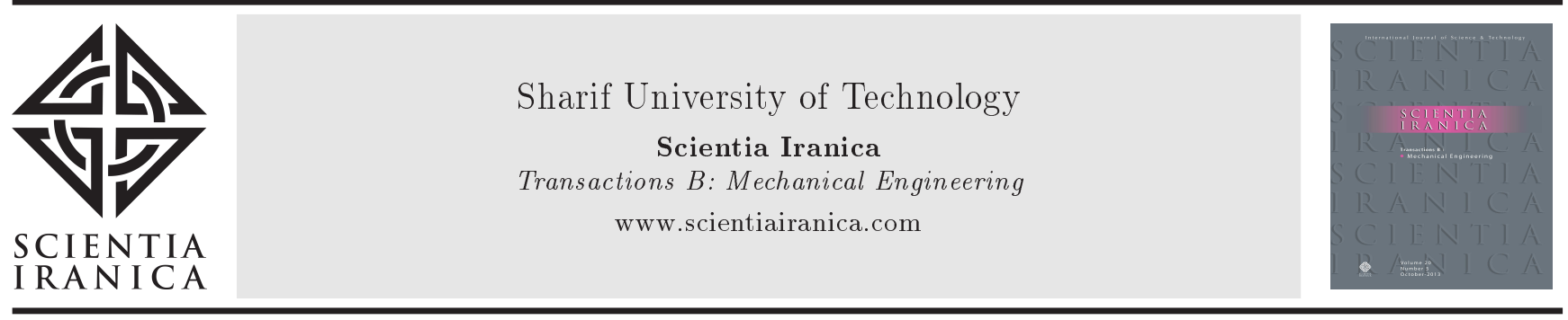

\title{
Feasibility study of a water-to-air heat pipe based heat exchanger for cooling load reduction and energy saving in the office buildings: A simulation study
}

\author{
M. Ahmadzadehtalatapeh* \\ Department of Marine \& Mechanical Engineering, Chabahar Maritime University, Chabahar, 99717-56499, Iran.
}

Received 8 April 2015; received in revised form 5 March 2016; accepted 10 May 2016

\section{KEYWORDS}

Energy consumption; Water-to-air heat pipe based heat exchanger; Indoor air;

TRNSYS.

\begin{abstract}
In the present investigation, the feasibility of cooling load and power consumption effect of a water-to-air heat pipe based heat exchanger (HPHX) on an office building was studied. An office building in Chabahar Maritime University, in southeast region of Iran, which is considered as a high cooling load demanding region, was chosen as the case study. The present research uses the TRNSYS software to investigate the hourly responses of the existing system added with the water-to-air HPHXs in terms of indoor air conditions and monthly power consumption. The effect of added water-to-air HPHXs on the system was determined, and the results were compared with the existing situation. Water-to-air HPHXs with two, four, and six numbers of rows were examined to recommend the most appropriate configuration for the system. According to the simulation findings, the existing system with the added six-row water-to-air HPHX is capable of establishing the convenient air into the office space. Moreover, it was shown that by implementation of the six-row water-to-air HPHX, a total amount of $3,108.57 \mathrm{kWh}$ power, which is about $42 \%$, could be saved in a year.

(C) 2017 Sharif University of Technology. All rights reserved.
\end{abstract}

\section{Introduction}

The primary energy demand for the year 2011 in Iran showed $2.5 \%$ increment compared to the year 2010 and it was projected that the electricity demand in Iran will be about 200,000 MW in 2030 [1]. Also, the statistics indicate that the residential and commercial sectors are the two major energy consuming sectors in the country [2]. It was also shown that ventilation and air conditioning systems account for more than $50 \%$ of the total power consumption in building sector. Therefore, there is a great energy saving potential in building sector, and engineers try to find new energy saving technologies to reduce the energy consumption. Heat pipe based heat exchangers (HPHXs) have the

*. Tel.: +985431272137

E-mail address: m_ahmadzadeh56@yahoo.com potential to achieve this objective. HPHX consists of heat pipe tubes that are filled with a refrigerant as the working fluid. The refrigerant absorbs the heat and evaporates in the evaporator section and condenses in the condenser section. The condensed liquid returns to the evaporator with the aid of the capillary action in heat pipes configuration in a horizontal position and the gravity in thermosyphons. HPHXs offer many advantages over the conventional heat exchangers. The advantages can be summarized as: compactness, reliability, no contamination, and minimum maintenance. An interesting point regarding the HPHXs operation is that the HPHXs do not require any external power to operate.

Literature survey showed that the applications of HPHX to reduce the energy consumption in air conditioning systems have already been investigated [312]. For instance, possible improvement in an air 
conditioning system performance by application of heat pipe technology was investigated by Naphon [3]. The study showed that the air conditioning system with three rows of heat pipes could provide the highest COP value with the increase of $6.4 \%$ in comparison to the conventional air conditioning system. Supirattanakul et al. [4] explored the application and working fluid type of a closed-loop oscillating heat pipe on the performance of a split type air conditioning system. Possible energy saving in air conditioning systems by application of HPHXs was explored for Indian climate zones [5]. The study revealed that the maximum energy saving potential occurs for the hot and dry, warm and humid, and composite Indian climatic zones. The energy saving capability and heat transfer of the $\mathrm{HPHX}_{\mathrm{s}}$ were investigated numerically by Hughes et al. [6]. According to the findings, application of the HPHX could lead to reduction of energy consumption from the air conditioning systems. In another research, Chaudhry and Hughes [7] investigated the passive airside cooling capability of heat pipes in response to gradually varying external temperatures for Doha, Qatar. The study proved that the HPHX has the potential to reduce the air temperature without the requirement of any mechanical intervention.

The impact of an air-to-air type HPHX on the performance of an air conditioning system in a library building in the tropics was investigated by Ahmadzadehtalatapeh [9]. The study revealed the positive effect of the added air-to-air type HPHX on the air conditioning system in terms of energy recovery and established indoor air conditions. In another attempt, Yau [10] examined a double HPHX configuration in a hospital operating theater to study its effect on the indoor air conditions and yearly energy consumption. The HPHXs were placed inside the ducting area, and the effect of added double HPHXs was investigated for a whole year. It was found that with the application of the double HPHX configuration, the total amount of $51,000 \mathrm{kWh}$ energy could be saved in a one-year operation. In another study, the effect of HPHX on an orthopaedic ward air conditioning system was reported [11]. For this purpose, a series of tests were performed to determine the empirical performance of an air-to-air type HPHX. The HPHX was added to the existing air conditioning system to investigate the resultant indoor air conditions and possible energy savings. Based on the results, the positive effects of the HPHX on the system were proved in terms of indoor air and energy savings.

Literature review indicated that almost in all of the studies, an air-to-air type of HPHXs was placed in the air conditioning system to perform an energy transfer between the two air flows in the ducting system. However, despite many practical implementations of the HPHXs, the investigation benefiting the heat removal capability of the water-to-air HPHXs from the occupied spaces of buildings is very limited and actually none, to the best knowledge of the author.

To this end, this study is conducted and the major aim is to explore the feasibility of cooling load reduction and energy savings in buildings by applying the water-to-air HPHXs. In this configuration, the water-to-air HPHX was planned to be placed inside the space rather than the ducting system of the air conditioning system. This investigation was conducted to determine the possible effects of the water-to-air

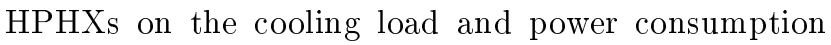
of an Office Building in Chabahar Maritime University (OBCMU), Iran, which is located in southeast region of the country. (Note: Considering the latest available monthly mean temperature for different regions of Iran, southeast region of the country as a high cooling load demanding region was considered as the case study, see Table 1).

The characteristics of the heat transfer of the

Table 1. Mean monthly temperature for different regions of Iran.

\begin{tabular}{lcccccc}
\hline Month & $\begin{array}{c}\text { Northwest } \\
\text { (Tabriz) }\end{array}$ & $\begin{array}{c}\text { North } \\
\text { (Tehran) }\end{array}$ & $\begin{array}{c}\text { Northeast } \\
\text { (Mashhad) }\end{array}$ & $\begin{array}{c}\text { Center } \\
\text { Esfahan) }\end{array}$ & $\begin{array}{c}\text { Southwest } \\
\text { (Bushehr) }\end{array}$ & $\begin{array}{c}\text { South } \\
\text { (Bandar Abbas) }\end{array}$ \\
\hline January & -3 & 2.4 & 0.1 & 2.9 & 14.1 & 18.1 \\
February & -1 & 4.8 & 2.2 & 5.3 & 15.5 & 19.3 \\
March & 5 & 10.2 & 7.7 & 10.5 & 19.4 & 23.1 \\
April & 11 & 16.2 & 13.9 & 15.6 & 23.4 & $\mathbf{2 6 . 4}$ \\
May & 17 & 22.3 & 19.7 & 21.3 & $\mathbf{2 8 . 9}$ & $\mathbf{3 1 . 2}$ \\
June & 22 & $\mathbf{2 7 . 5}$ & 24.3 & $\mathbf{2 6 . 7}$ & $\mathbf{3 0 . 6}$ & $\mathbf{3 3 . 3}$ \\
July & $\mathbf{2 6}$ & $\mathbf{3 0 . 9}$ & $\mathbf{2 6 . 7}$ & $\mathbf{2 9 . 4}$ & $\mathbf{3 2 . 8}$ & $\mathbf{3 4 . 4}$ \\
August & 25 & $\mathbf{2 9 . 5}$ & 24.7 & $\mathbf{2 7 . 9}$ & $\mathbf{3 2 . 7}$ & $\mathbf{3 4}$ \\
September & 21 & 25 & 19.5 & 23.2 & $\mathbf{3 0 . 1}$ & $\mathbf{3 2}$ \\
October & 14 & 18.2 & 13.4 & 16.9 & $\mathbf{2 6 . 7}$ & $\mathbf{2 9 . 7}$ \\
November & 6 & 11 & 7.6 & 9.7 & 20.7 & 23.9 \\
December & 0 & 5 & 2.7 & 4.5 & 16.3 & 19.8 \\
\hline
\end{tabular}


water-to-air HPHXs were theoretically determined. Then, the existing system and the system equipped with the water-to-air HPHXs were simulated hour-byhour, and the effect of water-to-air HPHXs on the space air conditions and energy savings was studied. To obtain the most desired conditions, water-to-air HPHXs with two, four, and six numbers of rows were examined. This feasibility study encourages the engineers for practical implementation of the water-toair HPHX in buildings to improve the energy performance.

\section{Research methodology}

In the present study, the feasibility of energy savings by the application of water-to-air HPHX to office buildings was theoretically investigated. For this purpose, the existing space was studied through simulation in TRNSYS studio, first in Section 3. Then, a waterto-air HPHX was planned to be installed in the space to study its potential for energy savings. The waterto-air HPHX thermal performance was determined using effectiveness-NTU approach to be defined as a component and added to the TRNSYS simulation studio. More details regarding the simulation process will be explained later in the sections below. The present research work is categorized into three main sections. In Section 3, the OBCMU will be studied in terms of indoor air conditions and energy consumption. Then, the system with the added water-to-air HPHXs will be described in Section 4. And, at the end in Section 5 , the results and discussions will be presented.

\section{Dynamic simulation for a year-round operation: The existing system and the system equipped with the water-to-air HPHXs}

\subsection{Existing system simulation in TRNSYS}

As already mentioned in the paper, an Office Building in Chabahar Maritime University (OBCMU), Iran, was chosen as the case study in this research. This office is the control room of the Information Technology Center and is located in the second floor of the building, as shown in Figure 1.

In order to estimate the effect of water-to-air $\mathrm{HPHX}_{\mathrm{s}}$ on the cooling loads and power consumption of the OBCMU, the existing system was simulated. To this end, the months, with out-of-the-range temperatures recommended for the human thermal comfort, were considered. Based on the ASHRAE [13], the recommended inside air temperature and $\mathrm{RH}$ for office buildings in summer are $23-26^{\circ} \mathrm{C}$ and $50-60 \%$, respectively. Therefore, as shown in Figure 2, seven months, in which ambient temperature is higher than standard comfort recommendations, were considered

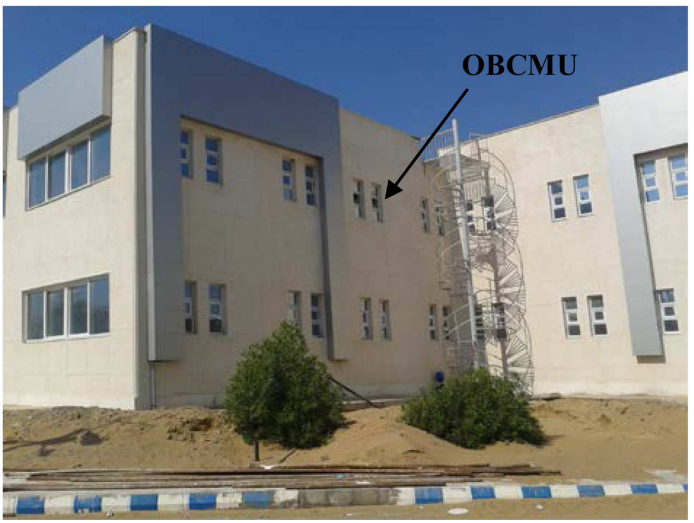

Figure 1. Overview of the OBCMU.

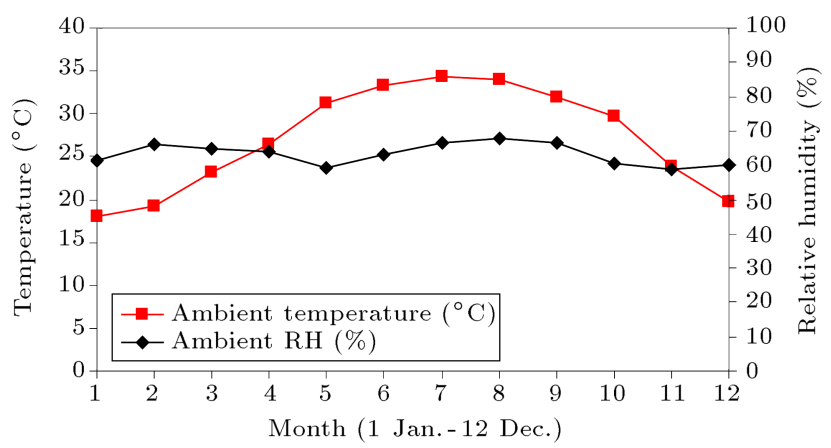

Figure 2. Monthly mean ambient temperature and RH of the region.

for the study. These months are April, May, June, July, August, September, and October.

TRNSYS simulation software, which is a flexible graphically-based software for the transient simulation of the cooling and heating systems in buildings, was used for hourly simulation of the systems in this study. The software consists of a library including most of the common components; however, the nonstandard components can be defined and added to the standard library and used for the simulation purposes. The components of the systems are assembled in the TRNSYS studio, and the software recognizes the description language in which the user defines the equipment and the manner in which the components are connected. In order to simulate the existing system (i.e., OBCMU), it was considered as a single thermal zone, and internal and architectural conditions of the building were defined as Type 56a. For this purpose, internal heat gains, the number of people, equipment, and walls position were defined to simulate the OBCMU. Figure 3 shows the simulation layout of the OBCMU. The components and functions in Figure 3 are tabulated in Table 2.

\subsection{Existing system simulation results}

The OBCMU inside air conditions were determined for the mentioned months of the year, and the mean values were tabulated in Table 3 . Figure 4 illustrates 
Table 2. The processes and functions in Figures 3 and 7.

\begin{tabular}{|c|c|c|}
\hline Code or label & $\begin{array}{l}\text { Description of } \\
\text { the components }\end{array}$ & Function \\
\hline Type 109-ТMY2 & Region weather data & $\begin{array}{l}\text { This component reads TRNSYS TMY } 2 \text { format } \\
\text { weather file to determine the outdoor condition. }\end{array}$ \\
\hline Type 56a & Building (space) & $\begin{array}{l}\text { This component takes the inlet DBT, RH, and } \\
\text { air flow and calculates the space DBT and RH. }\end{array}$ \\
\hline & Ambient related data & $\begin{array}{l}\text { This component takes the ambient air data } \\
\text { and calculates the fictive sky temperature. }\end{array}$ \\
\hline 药 & HPHX & $\begin{array}{l}\text { This component takes the inlet temperatures of } \\
\text { evaporate and condenser sections and calculates } \\
\text { the evaporator and condenser leaving temperatures. }\end{array}$ \\
\hline $\begin{array}{c}090 \\
\text { Type } 33 \mathrm{e}\end{array}$ & Psychrometric calculator & $\begin{array}{l}\text { This component takes any two properties of moist } \\
\text { air and calculates all other properties of moist air. }\end{array}$ \\
\hline Type $65 \mathrm{c}$ & Online plotter & $\begin{array}{l}\text { This component illustrates the simulated data on } \\
\text { the screen and saves them into a specified file. }\end{array}$ \\
\hline
\end{tabular}

Table 3. Existing system data (indoor air data).

\begin{tabular}{lcclcc}
\hline Month & $\boldsymbol{T}\left({ }^{\circ} \mathbf{C}\right)$ & $\mathbf{R H}(\boldsymbol{\%})$ & Month & $\boldsymbol{T}\left({ }^{\circ} \mathbf{C}\right)$ & RH (\%) \\
\hline April & 29.4 & 60.4 & August & 33.2 & 76.0 \\
May & 31.9 & 62.4 & September & 31.9 & 72.7 \\
June & 32.9 & 69.9 & October & 30.6 & 63.5 \\
July & 33.3 & 76.1 & & & \\
\hline
\end{tabular}

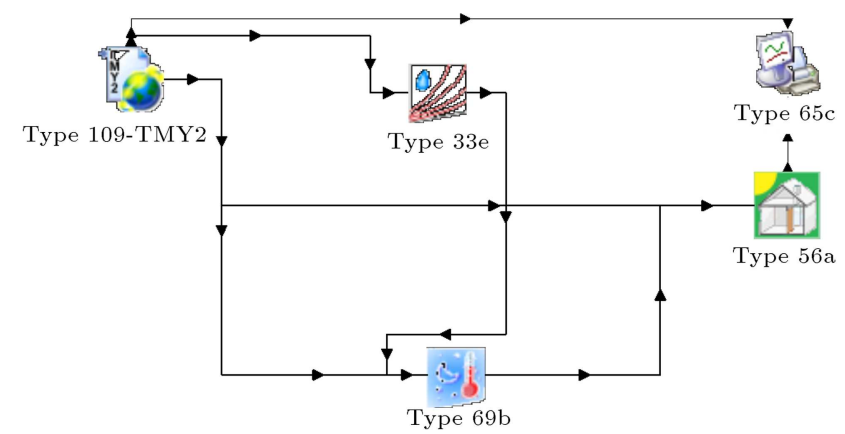

Figure 3. TRNSYS components to simulate responses of the OBCMU.

the inside air temperature and RH for typical June as the representative of the months studied. For instance, in June, the mean inside air temperature and $\mathrm{RH}$ are $32.9^{\circ} \mathrm{C}$ and $69.9 \%$, respectively. The required energy for conditioning the inside air to the design air conditions will be discussed later in the paper.

\section{System equipped with the water-to-air HPHXs}

\subsection{Water-to-air HPHX performance study}

Before determining the performance of the water-toair HPHXs, the operating principle of the water-to-

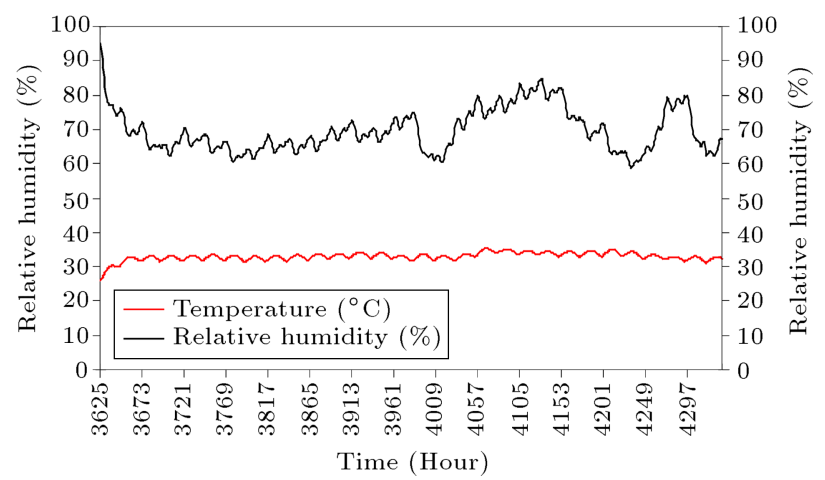

Figure 4. Simulation results for the existing system, typical June.

air HPHXs, which is planned to be added to the system, needs to be explained. The water-to-air HPHXs consist of two sections as the evaporator and the condenser sections. The refrigerant inside the tubes absorbs the heat from the air flowing through the evaporator section and rejects it to the cool water flowing through the condenser section. The heat pipe tubes in the evaporator section are externally-finned, while the tubes in condenser section are bare (i.e., no fins attached), as shown in Figure 5. The physical parameters of the considered water-to-air HPHXs are 
Table 4. Physical parameters of the considered water-to-air HPHX.

\begin{tabular}{ll}
\hline Water-to-air HPHXs dimensions & $300 \mathrm{~cm} \times 42 \mathrm{~cm}$ \\
Number of rows in the flow direction & Two, four, and six rows \\
Tubes arrangement & Staggered \\
Centre-to-centre tube spacing & Transverse: $31 \mathrm{~mm}$; Longitudinal: $27 \mathrm{~mm}$ \\
Fin & Aluminum corrugated, wavy plate, \\
& 12 fin per inch, thickness: $0.15 \mathrm{~mm}$ \\
Refrigerant & HFC family \\
\hline
\end{tabular}

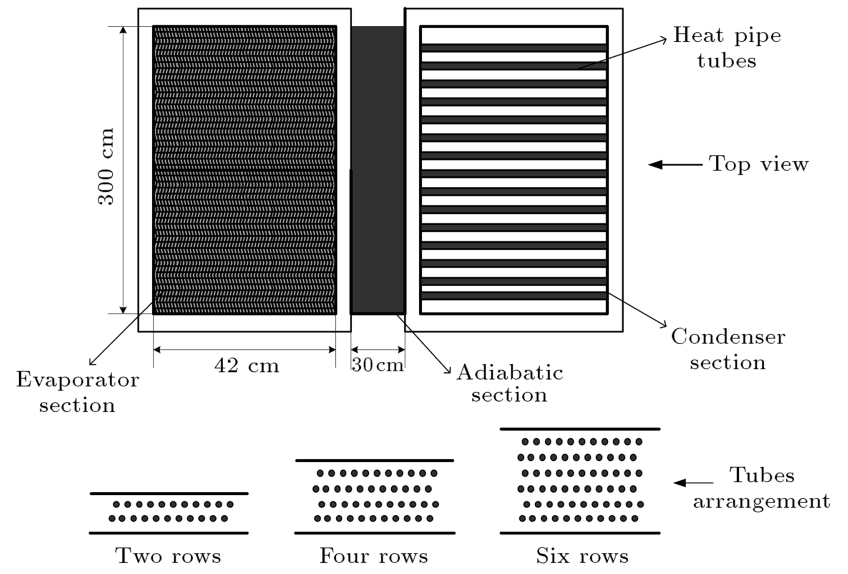

Figure 5. Schematic diagram of the water-to-air HPHXs.

presented in Table 4. The dimensions of the heat exchanger were chosen based on the available space of the OBCMU.

The effectiveness-NTU approach was used to simulate the thermal performance and characteristics of heat transfer of the water-to-air HPHXs in the present study [14]. For the constant specific heat and heat transfer properties throughout the heat exchanger, the effectiveness is recommended as [15]:

$$
\varepsilon=\frac{1-e^{-\mathrm{NTU}\left(1-C_{\min } / C_{\max }\right)}}{1-\left(C_{\min } / C_{\max }\right) e^{-\mathrm{NTU}\left(1-C_{\min } / C_{\max }\right)}} .
$$

In the evaporator and condenser sections, the warm air and cool water are in cross flow with vapor inside the heat pipe tubes; since the vapor inside the tubes is almost at the constant temperature, its specific heat, $c_{p}$, and capacity rate, $C_{v}$, can be approximated to infinity. As a result, $C_{e} / C_{v}=C_{c} / C_{v}=0$. Therefore, the effectiven ess-NTU equation for a single row waterto-air HPHX is as follows [16]:

For the evaporator section:

$$
\varepsilon_{e 1}=1-\exp (-\mathrm{NTU})_{e}
$$

For the condenser section:

$$
\varepsilon_{c 1}=1-\exp (-\mathrm{NTU})_{c}
$$

The NTU value for the evaporator and condenser sections is calculated from the following equations, respectively:

$$
\begin{aligned}
& (\mathrm{NTU})_{e}=\frac{(\mathrm{UA})_{e}}{C_{e}}, \\
& C_{e}=\left(\dot{m} c_{p}\right)_{e}, \\
& (\mathrm{NTU})_{c}=\frac{(\mathrm{UA})_{c}}{C_{c}}, \\
& C_{c}=\left(\dot{m} c_{p}\right)_{c} .
\end{aligned}
$$

The effectiveness-NTU approach provides the following equations for a HPHX with $n$ rows of heat pipes in the flow direction [16]:

For the evaporation section:

$$
\varepsilon_{e n}=\frac{\left(\frac{1-\frac{C_{e}}{C_{v}} \varepsilon_{e 1}}{1-\varepsilon_{e 1}}\right)^{n}-1}{\left(\frac{1-\frac{C_{e}}{C_{v}} \varepsilon_{e 1}}{1-\varepsilon_{e 1}}\right)^{n}-\frac{C_{e}}{C_{v}}} .
$$

For the condenser section:

$$
\varepsilon_{c n}=\frac{\left(\frac{1-\frac{C_{c}}{C_{v}} \varepsilon_{c 1}}{1-\varepsilon_{c 1}}\right)^{n}-1}{\left(\frac{1-\frac{C_{e}}{C_{v}} \varepsilon_{c 1}}{1-\varepsilon_{c 1}}\right)^{n}-\frac{C_{c}}{C_{v}}} .
$$

And, for $C_{e} / C_{v}=0$ and $C_{c} / C_{v}=0$, the above equations will be written in the form of:

$$
\varepsilon_{e n}=1-\left(1-\varepsilon_{e 1}\right)^{n},
$$

and:

$$
\varepsilon_{c n}=1-\left(1-\varepsilon_{c 1}\right)^{n} .
$$

Then, the overall effectiveness $(\varepsilon)$ of the heat exchanger is written as:

If $C_{e}>C_{c}$ :

$$
\varepsilon=\left(\frac{1}{\varepsilon_{c n}}+\frac{C_{c} / C_{e}}{\varepsilon_{e n}}\right)^{-1},
$$


and if $C_{c}>C_{e}$ :

$$
\varepsilon=\left(\frac{1}{\varepsilon_{e n}}+\frac{C_{e} / C_{c}}{\varepsilon_{c n}}\right)^{-1} .
$$

$U$ as the overall heat exchanger heat transfer coefficient can be written as [17]:

$$
U=\frac{1}{\left[R_{e . s, e}+R_{h . p}+R_{e . s, c}\right] A} .
$$

$R_{h . p}$ is the thermal resistance of the heat pipe structure, wall, and wick structure; thermal resistances as the dominant thermal resistances in the heat pipe structure were considered for this purpose [18,19].

To determine the external surface thermal resistance of the evaporator section $\left(R_{e . s, e}\right)$, the mean heat transfer coefficient $\left(\alpha_{\text {fin }}\right)$ can be estimated using the correlation for the airflow over the finned tube banks as:

$$
\mathrm{Nu}=\alpha_{\text {fin }} D_{\text {hydraulic }} / k_{\text {air }},
$$

and Nusselt number is given by Hewitt [20]:

$\mathrm{Nu}=0.19\left(\frac{a}{b}\right)^{0.2}\left(\frac{\zeta}{D_{\text {tube }}}\right)^{0.18}\left(\frac{L_{\text {fin }}}{D_{\text {tube }}}\right)^{-0.14} \operatorname{Re}^{0.65} \operatorname{Pr}^{0.33}$

The heat transfer in the external finned surface is determined using the fin efficiency [21].

$$
\eta_{\text {fin }}=\tanh \left(m L_{\mathrm{fin}}\right) /\left(m L_{\mathrm{fin}}\right)
$$

and:

$$
m=\left(\frac{2 \alpha_{\mathrm{fin}}\left(1+\delta_{\mathrm{fin}} / L_{\mathrm{fin}}\right)}{k_{\mathrm{fin}} \delta_{\mathrm{fin}}}\right) .
$$

Then, the thermal resistance between the air flow and the external surface can be estimated using Eq. (19):

$$
R_{e . s}=\frac{1}{\eta_{\mathrm{fin}} \alpha_{\mathrm{fin}} A_{\mathrm{fin}}} .
$$

The condenser section consists of bare tubes in contact with water flow. Therefore, to estimate the external surface thermal resistance of the condenser section $\left(R_{e . s, c}\right)$, the mean heat transfer coefficient can be estimated using the correlation for the liquid flow over the bank of bare tubes as:

$$
\mathrm{Nu}=\alpha D_{\text {tube }} / k_{\text {water }},
$$

and Nusselt number is given as [22]:

$$
\mathrm{Nu}=c_{1} 1.11 \operatorname{Re}^{c_{2}} \operatorname{Pr}^{0.33}
$$

The thermal resistance for $N$ tubular heat pipe wall and wick structure was given by Shah and Sekulic [17], respectively:

$$
\begin{aligned}
& R_{\mathrm{wall}}=\frac{\ln \left(D_{o} / D_{i}\right)_{\mathrm{wall}}}{2 \pi L_{\mathrm{tube}} N k_{\mathrm{wall}}}, \\
& R_{\mathrm{wick}}=\frac{\ln \left(D_{o} / D_{i}\right)_{\mathrm{wick}}}{2 \pi L_{\mathrm{wick}} N k_{\mathrm{eff}}} .
\end{aligned}
$$

The thermal conductivity of multiple layers of screen mesh material with the working fluid was given by Chang [23] as:

$$
\begin{aligned}
k_{\mathrm{eff}}= & \frac{k_{f}}{(1+A)^{2}}\left\{\psi ^ { 2 } A \left[\frac{\psi A}{\psi-\pi B\left(1-k_{f} / k_{s}\right) / 2}\right.\right. \\
& \left.+\frac{2[1+A(1-\psi)]}{\psi-\pi B\left(1-k_{f} / k_{s}\right) / 4}\right] \\
& \left.+\left[1+A(1-\psi)^{2}\right]\right\},
\end{aligned}
$$

where $B=D_{\text {wire }} / t, A=D_{\text {wire }} / w$, and $t$ is the thickness of a single layer of wire mesh.

The simulation was performed for different operating conditions, and the results for different evaporator coil face velocities and HPHXs numbers of rows as the two deciding parameters on the thermal performance of the HPHXs were presented in Table 5. As tabulated in Table 5 , the evaporator coil face velocity in the range of $0.5 \mathrm{~m} / \mathrm{s}$ to $2 \mathrm{~m} / \mathrm{s}$ with $0.5 \mathrm{~m} / \mathrm{s}$ increment was examined for the HPHXs. The condenser inlet water temperature was considered at the temperature range of $20^{\circ} \mathrm{C}$ to $24^{\circ} \mathrm{C}$ to achieve the cooling effect of the evaporator section. Condenser coil face velocity was considered within the range of $0.1 \mathrm{~m} / \mathrm{s}$ to $0.8 \mathrm{~m} / \mathrm{s}$, with the increment of $0.2 \mathrm{~m} / \mathrm{s}$. The simulation results showed that the condenser inlet coil face velocity and condenser inlet water temperature have no significant effect on the thermal performance of the HPHXs. The entering water to the condenser section is the normal water, and a stream from the water distribution system of the building can be used for this purpose. The condenser leaving water could also be added to the building hot water distribution system in case needed.

Table 5. Effectiveness (\%) of the water-to-air HPHXs.

\begin{tabular}{ccccc}
\hline & \multicolumn{4}{c}{ Evaporator coil face velocity } \\
\hline $\begin{array}{c}\text { Number } \\
\text { of rows }\end{array}$ & $\mathbf{0 . 5}$ & $\mathbf{1}$ & $\mathbf{1 . 5}$ & $\mathbf{2}$ \\
\hline Two-row & 63.72 & 50.27 & 42.32 & 36.87 \\
Four-row & 85.78 & 74.39 & 66.64 & 59.59 \\
Six-row & 93.46 & 85.87 & 79.18 & 73.43 \\
\hline
\end{tabular}




\subsection{Simulation of the system with the added water-to-air HPHXs}

After determining the performance of the water-to-air HPHXs, the water-to-air HPHXs were planned to be placed inside a ducting area, as illustrated in Figure 6. In this configuration, the evaporator section of the water-to-air HPHX, which was placed inside the space, performs as the cooling section, and the condenser section of the water-to-air HPHX performs as the heat rejection section.

To simulate the system with the added waterto-air HPHXs, water-to-air HPHXs are required to be defined as a new component in the TRNSYS library. To this end, the performance of the water-to-air HPHXs, which was determined in the previous section, was written in the form of input, output, and parameters in FORTRAN source code and defined as a new component (Type 285). The defined Type 285 component takes the evaporator and condenser entering temperatures and calculates the leaving temperatures. The water-to-air HPHXs component was used in the simulation studio, as shown in Figure 7. The components and functions in Figure 7 are explained in Table 2.

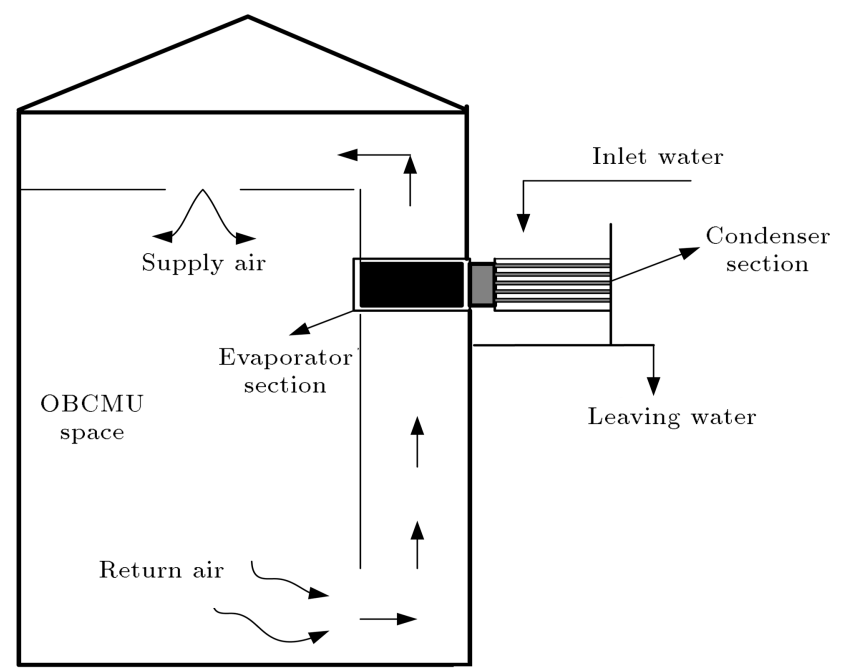

Figure 6. Schematic diagram of the OBCMU with the added water-to-air HPHX.

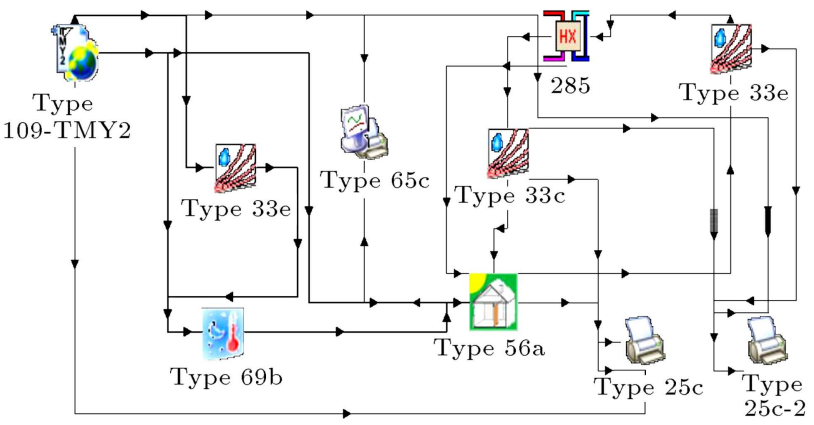

Figure 7. Simulation layout for the system with the added water-to-air HPHXs.
By application of the water-to-air HPHXs, the warm air passes through the evaporator section of the water-to-air HPHXs and its temperature decreases as its heat to the refrigerant is transferred inside the heat pipe tubes. Therefore, the cooled air distributes into the space from the diffusers, as illustrated in Figure 6 . The capabilities of the three water-to-air HPHXs with three different numbers of rows were examined to find out the most appropriate design in terms of the power savings.

\section{Simulation results and discussion}

As already explained, the system with the added water-to-air HPHXs was simulated for seven months, whose temperature was higher than the human thermal comfort requirements. The simulation results of the provided inside air conditions are presented in Figures 8 and 9 for typical August for the two- and six-row waterto-air HPHX as the representative of the simulations; the mean values are tabulated in Table 6 . It is clear that by placing the water-to-air HPHXs in the space, the indoor air conditions significantly improve. However, the comparison of the provided monthly temperature indicates that the space air conditions established by the added six-row water-to-air HPHX are

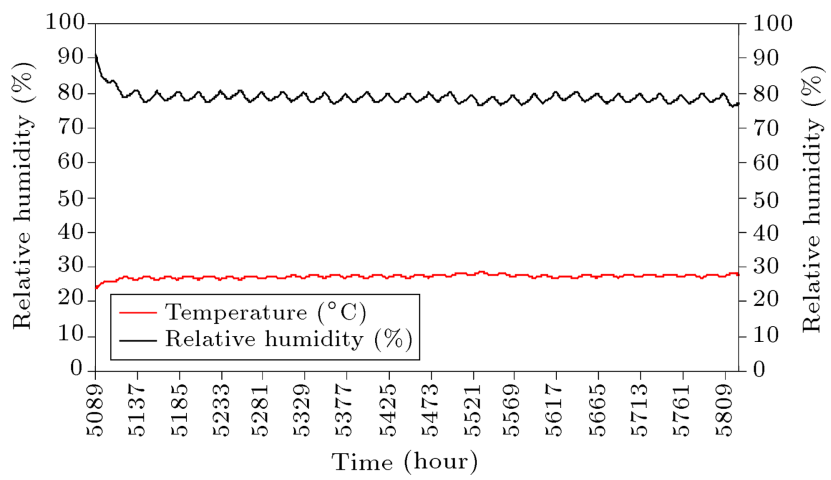

Figure 8. Simulation results for the system with the added two-row water-to-air HPHXs, typical August.

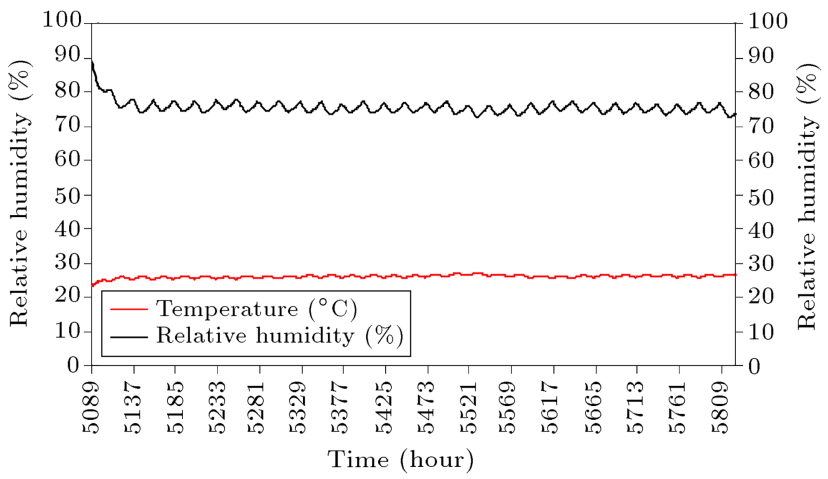

Figure 9. Simulation results for the system with the added six-row water-to-air HPHXs, typical August. 
Table 6. The simulation results for the system added with the water-to-air HPHXs.

\begin{tabular}{|c|c|c|c|c|c|c|c|c|c|c|c|c|c|c|}
\hline \multirow[b]{2}{*}{$\begin{array}{l}\text { Liquid-to } \\
\text { air HPHX }\end{array}$} & \multicolumn{2}{|c|}{ April } & \multicolumn{2}{|c|}{ May } & \multicolumn{2}{|c|}{ June } & \multicolumn{2}{|c|}{ July } & \multicolumn{2}{|c|}{ August } & \multicolumn{2}{|c|}{ September } & \multicolumn{2}{|c|}{ October } \\
\hline & $\begin{array}{c}\mathrm{T} \\
{ }^{\circ} \mathrm{C} \\
\end{array}$ & $\begin{array}{l}\text { RH } \\
(\%) \\
\end{array}$ & $\begin{array}{c}\mathrm{T} \\
{ }^{\circ} \mathrm{C} \\
\end{array}$ & $\begin{array}{l}\text { RH } \\
(\%) \\
\end{array}$ & $\begin{array}{c}\mathrm{T} \\
{ }^{\circ} \mathrm{C} \\
\end{array}$ & $\begin{array}{l}\text { RH } \\
(\%) \\
\end{array}$ & $\begin{array}{c}\mathrm{T} \\
{ }^{\circ} \mathrm{C} \\
\end{array}$ & $\begin{array}{l}\text { RH } \\
(\%) \\
\end{array}$ & $\begin{array}{c}\mathrm{T} \\
{ }^{\circ} \mathrm{C} \\
\end{array}$ & $\begin{array}{l}\text { RH } \\
(\%) \\
\end{array}$ & $\begin{array}{c}\mathrm{T} \\
{ }^{\circ} \mathrm{C} \\
\end{array}$ & $\begin{array}{l}\text { RH } \\
(\%) \\
\end{array}$ & $\begin{array}{c}\mathrm{T} \\
{ }^{\circ} \mathrm{C} \\
\end{array}$ & $\begin{array}{l}\text { RH } \\
(\%) \\
\end{array}$ \\
\hline Two-row & 25.1 & 75.2 & 26.5 & 77.5 & 27.0 & 78.2 & 27.3 & 78.6 & 27.2 & 78.9 & 26.5 & 79.9 & 25.8 & 78.8 \\
\hline Four-row & 24.4 & 76.4 & 25.6 & 75.6 & 26.1 & 75.6 & 26.3 & 75.9 & 26.2 & 76.2 & 25.6 & 77.4 & 25.0 & 77.5 \\
\hline Six-row & 24.2 & 76.5 & 25.4 & 74.9 & 25.8 & 74.8 & 26.0 & 75.2 & 25.9 & 75.5 & 25.4 & 76.7 & 24.8 & 76.9 \\
\hline
\end{tabular}

Table 7. Existing system heat needs to be removed and power consumption.

\begin{tabular}{lccccc}
\hline Month & $\boldsymbol{h}_{\boldsymbol{i} . \boldsymbol{a}}$ & $\boldsymbol{h}_{\boldsymbol{d} \boldsymbol{a}}$ & $\boldsymbol{\Delta} \boldsymbol{h}$ & $\begin{array}{c}\text { Power } \\
\text { input } \\
\mathbf{( k W )}\end{array}$ & $\begin{array}{c}\text { Monthly power } \\
\text { consumption } \\
(\mathbf{k W h})\end{array}$ \\
\hline April & 69.4 & 50.2 & 19.2 & 0.77 & 554.4 \\
May & 79.9 & 50.2 & 29.7 & 1.2 & 892.8 \\
June & 90.1 & 50.2 & 39.9 & 1.61 & $1,159.2$ \\
July & 97.2 & 50.2 & 47 & 1.9 & $1,413.6$ \\
August & 96.6 & 50.2 & 46.4 & 1.87 & $1,391.28$ \\
September & 88.0 & 50.2 & 37.8 & 1.52 & $1,094.4$ \\
October & 75.8 & 50.2 & 25.6 & 1.034 & 769.29 \\
Total & & & & & $7,274.97$ \\
\hline
\end{tabular}

in closer conditions to the ASHRAE recommendations, as shown in Table 6. Based on the simulation results, the six-row water-to-air HPHX could establish the mean temperatures of $24.2^{\circ} \mathrm{C}, 25.4^{\circ} \mathrm{C}, 25.8^{\circ} \mathrm{C}, 26^{\circ} \mathrm{C}$, $25.9^{\circ} \mathrm{C}, 25.4^{\circ} \mathrm{C}$, and $24.8^{\circ} \mathrm{C}$ for April, May, June, July, August, September, and October, respectively.

It seems that the provided $\mathrm{RH}$ values for the space are not within the recommended range and needs to be conditioned. In addition, the $\mathrm{RH}$ values higher than $70 \%$ can cause fungal contamination in the space and health problems. Therefore, auxiliary cooling equipment needs to be considered to keep the space air conditions within the standard recommendations.

Based on the provided space air conditions by the added water-to-air HPHXs, the six-row water-to-air HPHX is capable of establishing the most appropriate air into the space in terms of the temperature and $\mathrm{RH}$. Therefore, the space with the added six-row water-toair HPHX has been focused from the point of view of energy savings. To this end, the systems, i.e., the existing system and the system with the added six-row water-to-air HPHX, were simulated hour-by-hour for the seven months of operation. TMY weather data for the region were used for this purpose.

In order to provide reliable estimation of the cooling load and power consumption reducing capability of the added six-row water-to-air HPHX on the space, the provided indoor air conditions by the existing system and the system equipped with the six-row water-to-air HPHX needs to be compared with the design inside air conditions. In the existing system, the simulated inside air conditions were compared with the design air conditions, and the heat required to be removed from the space air was obtained using the Psychrometric chart. To this end, the enthalpies of the inside air $\left(h_{i . a}\right)$ and design air $\left(h_{\text {d.a }}\right)$ were drawn from the Psychrometric chart and compared, as tabulated in Table 7 . Based on the information, a split air-conditioning unit as the auxiliary cooling device was planned to be placed in the OBCMU to maintain the inside air within the recommended design range. The air-conditioning unit has the COP value of 2.65 and could meet the maximum cooling load of the space, which happens in July. The unit consumes $1.9 \mathrm{~kW}$ of power in a fullload operation. As tabulated in Table 7, the power consumption of the auxiliary air-conditioning unit in the operating months was determined based on the fullload operation mode and the heat must be removed in each individual month (i.e., $\Delta h$ ). The estimation shows that a total amount of $7,274.97 \mathrm{kWh}$ power is required to provide the design inside air conditions in operating months.

The heat must be removed from the space, and power consumption of the space with the added six-row water-to-air HPHX is also determined and compared with the existing system. This time, again, the enthalpy of the inside air and design air was obtained from the Psychrometric chart (see Table 8). As tabulated in Table 8, the cooling load reduction or heat removal from the space with the added six-row waterto-air HPHX is significant, which is $42.18 \%, 51.8 \%$, $60.9 \%, 64.89 \%, 64.89 \%, 59.52 \%$, and $48.04 \%$ for April, May, June, July, August, September, and October, respectively. Monthly power consumptions are also 
Table 8. Existing system with the added six-row water-to-air HPHX.

\begin{tabular}{lcccccccc}
\hline Month & $\boldsymbol{h}_{\boldsymbol{i . a}}$ & $\boldsymbol{h}_{\boldsymbol{d} . \boldsymbol{a}}$ & $\begin{array}{c}\boldsymbol{\Delta} \boldsymbol{h} \\
\text { without } \\
\mathbf{H P H X}\end{array}$ & $\begin{array}{c}\boldsymbol{\Delta} \boldsymbol{h} \\
\text { with } \\
\mathbf{H P H X}\end{array}$ & $\begin{array}{c}\text { Cooling } \\
\text { load } \\
\text { reduction } \\
(\mathbf{k J} / \mathbf{k g})\end{array}$ & $\begin{array}{c}\text { Cooling } \\
\text { load } \\
\text { reduction } \\
\mathbf{( \% )}\end{array}$ & $\begin{array}{c}\text { Power } \\
\text { consumption } \\
(\mathbf{k W})\end{array}$ & $\begin{array}{c}\text { Monthly } \\
\text { power } \\
\text { consumption } \\
(\mathbf{k W h})\end{array}$ \\
\hline April & 61.3 & 50.2 & 19.2 & 11.1 & 8.1 & 42.18 & 0.32 & 230.4 \\
May & 64.5 & 50.2 & 29.7 & 14.3 & 15.4 & 51.85 & 0.61 & 453.84 \\
June & 65.8 & 50.2 & 39.9 & 15.6 & 24.3 & 60.9 & 0.96 & 691.2 \\
July & 66.7 & 50.2 & 47 & 16.5 & 30.5 & 64.89 & 1.21 & 900.24 \\
August & 66.5 & 50.2 & 46.4 & 16.3 & 30.1 & 64.87 & 1.19 & 885.36 \\
September & 65.5 & 50.2 & 37.8 & 15.3 & 22.5 & 59.52 & 0.89 & 640.8 \\
October & 63.5 & 50.2 & 25.6 & 13.3 & 12.3 & 48.04 & 0.49 & 364.56 \\
Total & & & & & & & & $4,166.4$ \\
\hline
\end{tabular}

tabulated in Table 8. Based on the findings, the space would consume a total amount of $4,166.4 \mathrm{kWh}$ power to keep the inside air within the design conditions. A comparison between the existing system and the system equipped with the six-row water-to-air HPHX indicates that a total amount of $3,108.57 \mathrm{kWh}$ power would be saved in a year, which is about $42 \%$. In another term, by application of the water-to-air HPHX in the system, $86 \mathrm{kWh}$ of energy per unit area of the space could be saved.

By considering the above, it seems that the existing system equipped with the six-row water-to-air HPHX has a good potential for establishing convenient air into the OBCMU space. In addition, by placing the six-row water-to-air HPHX in the OBCMU, a considerable amount of power could be saved by cooling effect of the added water-to-air HPHXs.

\section{Conclusions}

The capability of the water-to-air HPHXs for cooling load and power consumption reduction was investigated in the present research. The investigation was conducted in an Office Building in Chabahar Maritime University (OBCMU), Iran, which is located in the southeast region of the country as a high cooling load demanding area. The existing system and the system with the added water-to-air HPHXs were simulated by using the TRNSYS software. The simulation was conducted for seven months of the year, which cooling load is required. The established indoor air with the help of water-to-air HPHXs with two, four, and six numbers of rows was examined, and the results were compared. Based on the simulation results, the indoor air temperature was maintained within the standard recommendations with the help of added six-row waterto-air HPHX. The results show that the provided indoor air temperatures with the added six-row waterto-air HPHX are $24.2^{\circ} \mathrm{C}, 25.4^{\circ} \mathrm{C}, 25.8^{\circ} \mathrm{C}, 26^{\circ} \mathrm{C}, 25.9^{\circ} \mathrm{C}$, $25.4^{\circ} \mathrm{C}$, and $24.8^{\circ} \mathrm{C}$ for April, May, June, July, August, September, and October, respectively. These values are within the range recommended by ASHRAE for office buildings.

The effect of added six-row water-to-air HPHX on the cooling load and power savings was also investigated. It was found that with the application of the sixrow water-to-air HPHX, the cooling load reduction of $64 \%$ could be achieved. In terms of power savings, the study indicates that a total amount of $3,108.57 \mathrm{kWh}$ power would be saved in a year, which is about $42 \%$.

\section{Acknowledgments}

The author would like to acknowledge the financial assistance received from the Chabahar Maritime University, Iran, for the author to conduct the research.

\section{Nomenclature}

$A \quad$ Heat transfer area $\left(\mathrm{m}^{2}\right)$

a Tube distance in a row in Eq. (16) $(\mathrm{mm})$

$b \quad$ Distance between the tubes in two successive rows in Eq. (16) (mm)

$c_{p} \quad$ Specific heat $(\mathrm{J} / \mathrm{kg} \cdot \mathrm{K})$

C Heat capacity $(\mathrm{J} / \mathrm{s} . \mathrm{K})$

$C_{1} \quad$ Constant in Eq. (21) (0.535)

COP Coefficient Of Performance

$D \quad$ Diameter $(\mathrm{m})$

HPHX Heat pipe based heat exchanger

$k \quad$ Thermal conductivity (W/m.k)

L Length (m)

$\dot{m} \quad$ Mass flow rate $(\mathrm{kg} / \mathrm{s})$

NTU Number of heat Transfer Units 


$\begin{array}{ll}\operatorname{Pr} & \text { Prandtl number } \\ \text { OBCM } & \text { Office Building Chabahar } \\ \mathrm{U} & \text { Maritime University } \\ R & \text { Thermal resistance }(\mathrm{k} / \mathrm{W}) \\ \mathrm{Re} & \text { Reynolds number } \\ n & \text { Number of rows } \\ N & \text { Number of the tubes } \\ \mathrm{Nu} & \text { Nusselt number } \\ \mathrm{RH} & \text { Relative Humidity }(\%) \\ t & \text { Thickness (m) } \\ \mathrm{TMY} & \text { Typical Meteorological Year } \\ T & \text { Temperature }\left({ }^{\circ} \mathrm{C}\right) \\ U & \text { Heat exchanger heat transfer coefficient } \\ & \left(\mathrm{W} / \mathrm{m}^{2 \circ} \mathrm{C}^{1}\right) \\ v & \text { Vapor } \\ w & \text { Opening width of the mesh (mm) }\end{array}$

\section{Greek letter}

$\begin{array}{ll}\varepsilon & \text { Effectiveness } \\ \zeta & \text { Fin spacing }(\mathrm{m}) \\ \alpha & \text { Heat transfer coefficient }\left(\mathrm{W} / \mathrm{m}^{2 \circ} \mathrm{C}^{1}\right) \\ \eta & \text { Fin efficiency } \\ \delta & \text { Fin thickness }(\mathrm{m}) \\ \psi & \text { Parameter dealing with the contact } \\ & \text { condition of wires in the mesh }\end{array}$

\section{Subscripts}

$\begin{array}{ll}a & \text { Air } \\ c & \text { Condenser } \\ \text { eff } & \text { Effective } \\ e . s & \text { External surface } \\ e & \text { Evaporator } \\ f & \text { fluid phase } \\ h \cdot p & \text { Heat pipe } \\ i & \text { Inner } \\ \text { max } & \text { Maximum } \\ \min & \text { Minimum } \\ o & \text { Outer } \\ S & \text { solid phase }\end{array}$

\section{References}

1. Hosseini, S.E., Mahmoudzadeh Andwari, A., Abdul Wahid, M. and Bagheri, G. "A review on green energy potentials in Iran", Renew. Sust. Energ. Rev., 27, pp. 533-545 (2013).

2. Mohammadnejad, M., Ghazvini, M., Mahlia, T.M.I. and Andriyana, A. "A review on energy scenario and sustainable energy in Iran", Renew. Sust. Energ. Rev., 15, pp. 4652- 4658 (2011).

3. Naphon, P. "On the performance of air conditioner with heat pipe for cooling air in the condenser", Energ. Convers. Manage., 51, pp. 2362-2366 (2010).

4. Supirattanakul, P., Rittidech, S. and Bubphachot, B. "Application of a closed-loop oscillating heat pipe with check valves (CLOHP/CV) on performance enhancement in air conditioning system", Energ. Buildings, 43, pp. 1531-1535 (2011).

5. Jadhav, T.S. and Lele, M.M. "Theoretical energy saving analysis of air conditioning system using heat pipe heat exchanger for Indian climatic zones", Int. $J$. Eng. Sci., Tech., 18, pp. 669-673 (2015).

6. Hughes, B.R., Chaudhry, H.N. and Calautit, J.K. "Passive energy recovery from natural ventilation air streams", Appl. Energ., 113, pp. 127-140 (2014).

7. Chaudhry, H.N. and Hughes, B.R. "Climate responsive behavior of heat pipe technology for enhanced passive airside cooling", Appl. Therm. Eng., 136, pp. 32-42 (2014).

8. Calautit, J.K., Chaudhry, H.N., Hughes, B.R. and Ghani, S.A. "Comparison between evaporative cooling and a heat pipe assisted thermal loop for a commercial wind tower in hot and dry climatic conditions", Appl. Energ., 101, pp. 740-755 (2013).

9. Ahmadzadehtalatapeh, M. "An air-conditioning system performance enhancement by using heat pipe based heat recovery technology", Sci. Iran. B, 20(2), pp. 329-336 (2013).

10. Yau, Y.H. "The use of a double heat pipe heat exchanger system for reducing energy consumption of treating ventilation air in an operating theatre - A full year energy consumption model simulation", Energ. Buildings, 40, pp. 917-925 (2008).

11. Ahmadzadehtalatapeh, M. and Yau, Y.H. "The application of heat pipe heat exchangers to improve the air quality and reduce the energy consumption of the air conditioning system in a hospital ward - A full year model simulation", Energ. Buildings, 43, pp. 23442355 (2011).

12. Jouhara, H. and Meskimmon, R. "Experimental investigation of wraparound loop heat pipe heat exchanger used in energy efficient air handling units", Energy, 35, pp. 4592-4599 (2010).

13. ASHRAE, ASHRAE Handbook, HVAC Applications (SI) (2007).

14. Kays, W.M. and London, A.L., Compact Heat Exchangers Design, McGraw-Hill, New York, USA (1984).

15. Incropera, F.D. and DeWitt, D.P., Fundamentals of Heat and Mass Transfer, 4th Edn. John Wiley \& Sons, New York, USA (1996). 
16. Noie, S.H. "Investigation of thermal performance of an air-to-air thermosyphon heat exchanger using $\varepsilon$-NTU method", Appl. Therm. Eng., 26, pp. 559-567 (2006).

17. Shah, R.K. and Sekulic, D.P., Fundamentals of Heat Exchanger Design, John Wiley \& Sons, New Jersey, USA (2003).

18. Peterson, G.P., An Introduction to Heat Pipes: Modeling, Testing, and Applications, John Wiley \& Sons, New York, USA (1994).

19. Dunn, P.D. and Reay, D.A., Heat Pipes, 4th Ed, Pergamon Press, Oxford, UK (1994).

20. Hewitt, G.F., Heat Exchanger Design Handbook, Begell House (1998).

21. Rohsenow, W.M., Hartnett, J.P. and Cho, Y.I., Handbook of Heat Transfer, 3th Ed., McGraw-Hill (1998).

22. Holman, J.P., Heat Transfer, 8th Edn., McGraw-Hill (1996).
23. Chang, W.S. "Porosity and effective thermal conductivity of wire screens", ASME J. Heat Trans., 112(1), pp. 5-9 (1990).

\section{Biography}

Mohammad Ahmadzadehtalatapeh received BSc and MSc degrees in Mechanical Engineering from Tabriz University and Ferdowsi University of Mashhad, Iran, in 2000 and 2002, respectively. He obtained his $\mathrm{PhD}$ degree in Mechanical Engineering in 2011 from the University of Malaya, Malaysia. He is currently an Assistant Professor in the Chabahar Maritime University, Iran. His research interest areas are heat pipe heat exchangers, air-conditioning systems, and energy saving in buildings. 